\title{
AS CONTRIBUIÇÕES DA FILOSOFIA HEIDEGGERIANA NAS PESQUISAS SOBRE O CUIDADO EM ENFERMAGEM
}

Marianne Rocha Duarte', Silvana Santiago da Rocha²

\begin{abstract}
RESUMO: Este artigo tem por objetivo refletir sobre as contribuições da fenomenologia heideggeriana para a compreensão das dimensões do cuidado em enfermagem. Embora o cuidado tenha sido foco de diversos estudos na tentativa de compreender seu significado, percebe-se uma lacuna nas pesquisas em relação à compreensão das dimensões existenciais do ser humano. Neste sentido, as pesquisas sobre o cuidado em enfermagem utilizando o referencial filosófico de Martin Heidegger possibilitariam aos profissionais e futuros profissionais refletir sobre sua prática, desvelar a si mesmo e ao mundo ao seu redor, tornando-se profissionais mais atentos e reflexivos para que possam cuidar de forma mais autêntica, ao tempo em que a Enfermagem desvela o sentido do seu cuidado.

PALAVRAS-CHAVE: Enfermagem; Cuidados de enfermagem; Pesquisa em enfermagem.

\section{THE CONTRIBUTIONS OF HEIDEGGARIAN PHILOSPHY IN RESEARCH ABOUT CARE IN NURSING}

\begin{abstract}
This article aims to reflect on the contributions of Heideggerian phenomenology to the comprehension of dimensions of care in Nursing. Although care has been the focus of various studies in an effort to understand its significance, one can see a research gap in relation to the existential dimensions of the human being. In this sense, research on nursing care using Martin Heidegger's philosophy would make it possible for health professionals and future health professionals to reflect on their practice, appearing more clearly to themselves and the world around them, and becoming more attentive and reflexive health professionals, able to care in a more authentic manner at the same time as Nursing shows the meaning of its care.
\end{abstract}

KEYWORDS: Nursing; Nursing Care; Nursing Research.

\section{LAS CONTRIBUCIONES DE LA FILOSOFÍA HEIDEGGERIANA EN LAS INVESTIGACIONES SOBRE EL CUIDADO EN ENFERMERÍA}

RESUMEN: Este artículo tiene por objetivo reflexionar sobre las contribuciones de la fenomenología heideggeriana para la comprensión de las dimensiones del cuidado en enfermería. A pesar de el cuidado ser foco de diversos estudios en la tentativa de comprender su significado, se percibe una laguna en las investigaciones referentes a la comprensión de las dimensiones existenciales del ser humano. En este sentido, los trabajos sobre el cuidado en enfermería utilizando el referencial filosófico de Martin Heidegger posibilitarían a los profesionales y futuros profesionales reflexionar sobre su práctica, desvelar a sí mismos y al mundo alrededor, tornándose profesionales más atentos y reflexivos para cuidar de modo más auténtico, al mismo tiempo que la Enfermería desvela el sentido de su cuidado.

PALABRAS CLAVE: Enfermería; Cuidados de enfermería; Investigación en enfermería.

${ }^{1}$ Enfermeira. Mestre em Enfermagem.

${ }^{2}$ Enfermeira. Doutora em Enfermagem. Professora do Departamento de Enfermagem e do Programa de Pós-Graduação em Enfermagem da Universidade Federal do Piauí.

Autor correspondente:

Marianne Rocha Duarte

Universidade Federal do Piauí

R. São José, 33 - 65630-060 - Timon-MA-Brasil.

Recebido: $17 / 09 / 10$

E-mail: marianneduarte26@hotmail.com

Aprovado: 21/01/11 


\section{INTRODUÇÃO}

A experiência de cuidar pode ser considerada como parte essencial do processo humano, como um modo de assegurar a manutenção da existência. O homem, desde a sua mais tenra idade, necessita de cuidado para manifestar-se plenamente como ser no mundo e, por isso, podemos afirmar que o cuidado domina o homem enquanto ele viver.

A ação de cuidar sempre esteve presente na história da humanidade, como maneira de viver, de se relacionar no mundo, acompanhando o ser humano desde a sua gênese. Nos primórdios das civilizações o cuidado era desenvolvido como uma forma de sobrevivência, de defesa da espécie, sendo realizado de forma empírica, embasado nas forças místicas e na ação da natureza, sendo prestado e recebido sem um conhecimento prévio do que era realizado ${ }^{(1)}$.

Com o Cristianismo e a instituição de ordens religiosas, o cuidado ganha uma nova conotação, caracterizando-se por seu sentido religioso de prestar ajuda e oferecer apoio espiritual ${ }^{(2)}$. Posteriormente com o surgimento dos hospitais, o cuidado torna-se institucionalizado e surge a necessidade de treinar pessoas para, entre outros, administrar medicamentos, limpar feridas e desempenhar atividades de conforto junto aos doentes. Nesse contexto é que surge a Enfermagem ${ }^{(3)}$.

Com o início da profissionalização da Enfermagem, realizada por Florence Nightingale em meados do século XIX, o cuidado assume uma característica formal e adquire o status de uma ocupação distinta. Durante a fase nightingaliana, o cuidado passa a ter um caráter organizado e as ações de enfermagem são expressas de forma holística, uma vez que elas extrapolavam o contexto hospitalar, contemplando também o contexto social, político e ecológico.

A partir do século XX, as técnicas de enfermagem se intensificam, instrumentalizando assim o cuidado de enfermagem. O avanço da tecnologia faz com que a prática de cuidado enfatize a abordagem biomédica, tendo a doença como foco central do cuidado e o ser cuidado sendo identificado pela sua patologia, desconsiderando-se a sua história ${ }^{(4)}$. Nessa perspectiva, o cuidado deixa de ter seu valor central e a ênfase se direciona para as ciências biológicas/tecnicistas, voltando-se para dar respostas ao diagnóstico e prescrição médica.

Até este período, a Enfermagem era vista como não científica e suas ações baseavam-se apenas na intuição. Sendo assim, na tentativa de ser reconhecida como ciência e consolidar-se como um campo específico do saber, a Enfermagem inicia uma fase de construção de um corpo de conhecimentos próprios para fundamentar a sua prática profissional. O instrumental construído para orientar a Enfermagem na busca de sua autonomia foram as Teorias de Enfermagem, que permitiram delimitação da atuação com outros profissionais ${ }^{(5)}$.

Nesse contexto, entende-se que o processo de cuidar tem evoluído em sua trajetória histórica, sendo compreendido como essência da Enfermagem. Ele transcende, porém, os aspectos biológicos e psicossociais do indivíduo, e envolve aspectos como atenção, amor, respeito e compreensão do ser cuidado.

Assim, embora o cuidado tenha sido até hoje foco de diversos estudos e reflexões da Enfermagem, na tentativa de compreender o seu significado, e no intuito de planejar e discutir ações que otimizem e/ou melhorem a maneira como se cuida, percebe-se uma lacuna nas pesquisas no que diz respeito à compreensão das dimensões existenciais do ser humano que é cuidado, assim como daquele que cuida. Portanto, diante desta realidade, a Enfermagem deve dar continuidade à produção do conhecimento nesse campo, amparada também em correntes de pensamento voltadas para a dimensão ontológica, existencial.

$\mathrm{Na}$ perspectiva de olhar a dimensão existencial do cuidado, as pesquisas em Enfermagem têm a possibilidade de empregar a abordagem fenomenológica, utilizando como referencial o filósofo Martin Heidegger. Esta proposta metodológica propicia um conhecimento original sobre o "outro", a partir, da descrição de quem vivencia o fenômeno. Em outras palavras, a utilização dos conceitos heideggerianos na pesquisa procura elucidar o sentido do SER, partindo das situações experienciadas por este.

Assim, diante deste quadro, nos propomos fazer uma reflexão crítica sobre as contribuições da fenomenologia heideggeriana para a compreensão das dimensões do cuidado em Enfermagem, com vistas a propiciar uma discussão de que a filosofia heideggeriana é uma possibilidade para as pesquisas envolvendo o cuidado de enfermagem.

\section{MÉTODO HEIDEGGERIANO: POSSIBILIDADE DE INVESTIGAÇÃO NO CUIDADO DE ENFER- MAGEM}

O método heideggeriano permite chegar à compreensão do ser, partindo da descrição das situações vivenciadas pelos indivíduos. Constitui-se em questionar 
o ser, interrogando o ente e buscando o sentido do ser. Heidegger procura descrever, explicar e compreender as diversas manifestações do sentido do ser, em todas as suas dimensões e, para tanto, parte da interrogação do que ele denomina de Dasein, expressão alemã que significa "ser-aí".

O ser é a maneira como algo se torna presente, manifesto, percebido e conhecido para o ser humano, designado por ele como um ser-aí, pois está inserido em um mundo, não sendo possível a sua concepção como um ser isolado, mas sempre um ser-no-mundo ${ }^{(6)}$.

O Dasein, enquanto ser-no-mundo, é um ser lançado no mundo. Há dois modos de estar-no-mundo, e que consistem na existência autêntica que é um modo próprio de ser, e na existência inautêntica caracterizada como um modo impróprio de ser. A existência autêntica refere-se à propriedade do existir, em que o Dasein torna-se si mesmo ao reconhecer-se enquanto um ser de presença, que pretende libertar-se do anonimato e da impessoalidade ${ }^{(7)}$. Já a existência inautêntica caracteriza-se como uma impropriedade, ou seja, uma esfera da existência que segue sem direção própria ${ }^{(8)}$. $\mathrm{Na}$ inautenticidade, as possibilidades de ser-no-mundo são projetadas nos objetos e o mundo passa a ser o foco de preocupação. Neste modo de existir, o homem evita toda a responsabilidade pessoal, aceitando as opiniões e normas que vêm da massa. O eu individual abandona a possibilidade de "ser si próprio" e perde-se no meio do todo, torna-se anônimo, impróprio.

$\mathrm{Na}$ existência inautêntica, o homem vive uma abertura que não lhe pertence e assim ele seria um ser que se projeta para fora de si mesmo, permanecendo nas fronteiras de seu próprio mundo, vivendo de modo indiferente ao mundo que o envolve ${ }^{(6)}$

É importante destacar ainda que o Dasein, enquanto "ser-com", está em constante contato com outros entes, e é desta relação que surge o cuidado. De acordo com Heidegger, o "cuidado é um modo de proceder com os entes envolventes no mundo"(7:83). Neste sentido, o cuidado como estrutura fundamental do ser-aí, assume a forma de solicitude e pode manifestar-se de duas formas. Uma que consiste em retirar o cuidado do outro e tomar-lhe o lugar (estar-junto- $a$ ) e outra em que se pode devolver o cuidado ao ser cuidado como uma possibilidade existencial de ser, não the retirando o cuidado (ser-com $)^{(7)}$. Em outras palavras, o primeiro modo de cuidar corresponde ao cuidado dominador, onde tudo é feito pelo outro, enquanto que o segundo refere-se ao cuidado que dá condições ao outro de crescer e assumir o seu próprio caminho.
Assim, esse cuidado, considerado como essência da existência humana é, portanto, essencial na prática de Enfermagem. Tal afirmativa justificaria, então, a busca da compreensão do significado da experiência vivida do ser que recebe e/ou daquele que oferece seus cuidados a outrem.

Ao buscar a compreensão do significado da experiência vivida pelos seres humanos, utilizando, na grande maioria das vezes, o método fenomenológico de investigação, tem-se alcançado valiosas contribuições para o conhecimento das diversas dimensões que envolvem o cuidado no processo de viver humano, que até então se encontravam inexploradas. Esta alternativa de investigação tem possibilitado à Enfermagem compreender o homem em seu todo, e não mais isoladamente ou em partes, além de ter permitido a compreensão do homem situado no mundo, em sua totalidade de $\operatorname{vida}^{(9)}$.

Neste sentido, a fenomenologia seria o caminho para que a Enfermagem pudesse investigar os fenômenos que envolvem o processo de cuidar do outro. Este cuidar revela facetas tão singulares e autênticas que a fenomenologia poderia desvelar as vivências dos profissionais e conhecendo aspectos do vida de clientes que se encontravam presos pelas distrações do cotidiano e que comumente impedem que estes possam agir com autenticidade ${ }^{(10)}$.

Em outras palavras, queremos dizer que os profissionais de Enfermagem têm, no mundo contemporâneo, enfatizado, nas suas ações de cuidado, muito mais a eficiência e o domínio técnico na realização dos procedimentos ${ }^{(11)}$, sem se preocupar com a pessoa enquanto ente envolvente, no sentido de promover uma possibilidade para o seu poder-ser na perspectiva da busca e valorização do próprio ser.

Acrescido a este aspecto, enfatiza-se que os profissionais envolvidos no cuidado ao ser doente, principalmente os da Enfermagem, apresentam uma tendência de fugir da responsabilidade de serem si mesmos, deixando, em muitos momentos, guiar-se pela situação, não tomando iniciativas, pois tudo em seu cotidiano já está decidido. Esta realidade configura-se portanto, como um modo de estar-nomundo inautenticamente.

Portanto, a partir desta constatação, é imprescindível que o cuidado seja assumido de forma autêntica, com intenção terapêutica, de zelo e ajuda. Os enfermeiros e demais membros da equipe precisam se voltar para a proclamação deste fazer, de forma a serem percebidos como seres que cuidam de outros seres, 
com preocupação autêntica, de forma profissional, terapêutica, científica e humana, objetivando alcançar a saúde e bem-estar de quem cuidam; proporcionandolhes liberdade e condições para vivenciar as próprias possibilidades de ser.

Diante da necessidade de despertar os profissionais de Enfermagem, bem como os graduandos em Enfermagem, para a natureza reflexiva de seu existir no mundo, a fim de que estes adquiram a autenticidade necessária no processo de cuidar do outro e assim dar mais sentido as suas ações, acredito ser de extrema importância o incentivo às pesquisas sobre o cuidado em Enfermagem utilizando a fenomenologia heideggeriana. Esta abordagem possibilitaria aos profissionais dar sentido as suas vivências e atividades, tornando-se profissionais mais atentos e reflexivos sobre a realidade e o modo de ser dos outros.

\section{CONSIDERAÇÕES FINAIS}

O enfoque fenomenológico objetiva desvelar a cotidianidade do mundo do ser, onde a experiência se passa através da descrição de suas vivências. Esta abordagem permite a compreensão do ser, valorizandoo e permitindo ser presença ao lidar com-o-outro.

Assim, esta reflexão nos mostra que a Enfermagem necessita rever a sua forma de cuidar, pois muitos de seus profissionais vivem um dia-a-dia determinado pela inautenticidade, que é um modo próprio do ser dos entes no cotidiano. Desse modo, as pesquisas sobre o cuidado em Enfermagem, utilizando o referencial filosófico de Martin Heidegger, possibilitariam aos profissionais e acadêmicos refletir sobre sua prática, desvelar a si mesmos e ao mundo ao seu redor, e compreender-se como ser-com-os-outros para que possam cuidar de forma mais autêntica.

Essa reflexão também nos remete à possibilidade de, por meio da fenomenologia heideggeriana, desvelarmos a compreensão do sentido que o cuidado tem em nossas vidas enquanto profissionais de Enfermagem e, a partir disso, subsidiar mudanças nas práticas de cuidado de Enfermagem, com modelos de atuação da equipe que contribuam com o desenvolvimento dos seres humanos enquanto seres de cuidado.

\section{REFERÊNCIAS}

1. Zeferino MT, Santos VEP, Wall ML, Rocha PK, Blois JM, Meireles BHS. Concepções de cuidado na visão de doutorandas de enfermagem. Rev Enferm UERJ. 2008;16(3):345-50.
2. Waldow VR. Cuidar: expressão humanizadora de enfermagem. Petrópolis: Vozes; 2006.

3. Waldow VR. Cuidado humano: o resgate necessário. $3^{\mathrm{a}}$ ed. Porto Alegre: Sagra Luzzatto; 2001.

4. Dias SMZ, Motta MGC. Práticas e saberes do cuidado de enfermagem à criança hospitalizada. Ciênc Cuid Saúde. 2004;3(1):41-54.

5. Almeida MCP, Mishima SM, Pereira MJB, Palha PF, Fortuna CM, Matumoto S. Enfermagem enquanto disciplina: que campo de conhecimento identifica a profissão? Rev Bras Enferm. 2009;62(5):748-52.

6. Sales CA. Ser-no-mundo e o cuidado humano: concepções heideggerianas. Rev Enferm UERJ. 2008;16(4):563-8.

7. Santos RB. Homens com câncer de próstata: um estudo da sexualidade à luz da perspectiva heideggeriana [dissertação]. Ribeirão Preto (SP): Universidade de São Paulo; 2006.

8. Ser e tempo. Trad. de Márcia Sá Cavalcante Schuback. $14^{\mathrm{a}}$ ed. Petrópolis: Vozes; 2005. Parte I.

9. Corrêa AK. Fenomenologia: uma alternativa para a enfermagem. Rev Latino-Am Enfermagem. 1997;5(1):83-8.

10. Monteiro CF, Rocha SS, Paz EPA, Souza IEO. Fenomenologia heideggeriana e sua possibilidade na construção de estudos de enfermagem. Esc Anna Nery. 2006;10(2):297-300.

11. Kletemberg DC, Mantovani MF, Lacerda MR. Entre a teoria e as práticas do cuidar: que caminho trilhar? Cogitare Enferm. 2004;9(1):94-9. 